\title{
Report
}

\section{Practice and Research on Group Teaching in Agricultural Application-oriented Universities}

\author{
Feng Shasha, Zhang Xiaohong", Tian Xiaoming* \\ College of Agriculture and Forestry, Hebei North University, Zhangiiakou, P. R. China \\ Email address: \\ fengshasha@yeah.net (Feng Shasha) \\ ${ }^{*}$ Corresponding author
}

\section{To cite this article:}

Feng Shasha, Zhang Xiaohong, Tian Xiaoming. Practice and Research on Group Teaching in Agricultural Application-oriented Universities. Teacher Education and Curriculum Studies. Vol. 6, No. 3, 2021, pp. 89-93. doi: 10.11648/j.tecs.20210603.13

Received: August 3, 2021; Accepted: August 13, 2021; Published: August 26, 2021

\begin{abstract}
Agricultural application-oriented colleges and universities often have great differences in the composition of students and uneven learning ability. The traditional classroom teaching mode dominated by teachers leads to low attendance and rise rate of students. How to give full play to students' enthusiasm and initiative and what teaching methods can improve the quality and effect of teaching are urgent problems to be solved. Combined with the author's teaching practice in agronomy related majors, this paper intends to carry out group teaching in the teaching of different courses such as subject basic courses, professional courses and practical courses, and use specific cases to illustrate the four aspects of curriculum design, group basis, project driven group teaching implementation and how to evaluate the effect of group teaching. The results show that group teaching has changed the situation that only teachers teach, mobilized students to actively participate, promoted the cognition, digestion, mastery and absorption of knowledge and skills in professional practice and independent thinking through division of labor and cooperation within groups and competition and answer between groups, and accumulated practical experience for future graduation design and future work, It is conducive to promoting the all-round development of students' comprehensive quality. Through the research of this project, we explore a set of scientific and effective group teaching methods for undergraduate agriculture related education in Colleges and universities.
\end{abstract}

Keywords: Group Teaching, Agriculture, Undergraduate Education

\section{Introduction}

Agricultural Application-oriented Undergraduate Colleges and universities are located in Colleges and universities for the cultivation of agricultural application-oriented talents. The enrollment scope of such colleges and universities includes ordinary college entrance examination and counterpart single enrollment. The composition of students varies greatly, and the learning ability is uneven. It is difficult for teachers to take care of students at all levels within limited teaching time. Some do not understand, and some have learned. In the long run, Only the teacher speaks in class. Therefore, how to effectively improve students' attendance and rise rate, give full play to students' enthusiasm and initiative, and finally improve teaching quality and teaching effect? Group teaching is an effective teaching method, that is, group cooperative learning.
Based on classroom teaching, students as the main body and teachers as the guidance, reasonably guide students to cooperate, and form a learning model in which intra group cooperation and inter group competition coexist $[1,2]$.

So far, the practice of group teaching mainly focuses on sports, vocal music, English, social work and other disciplines. Many educators first implement the research of group teaching in primary and secondary schools [3], summarize experience and evaluate the effect. In theory, some discuss the role of teaching characters in groups, such as stimulating thought cremation, cultivating competitive consciousness, enhancing communication skills and promoting team cooperation [4]; For example, activate the classroom atmosphere, stimulate students' interest and improve learning 
efficiency [5]. Some discuss the characteristics of this teaching method: specific applicable objects, special organizational forms, and special touch of teaching words [6]. Some research groups have different patterns, such as internal and external groups, ability groups or elective groups [7]. Some researchers reflect on the advantages and disadvantages of group teaching: the advantages are cooperation, diversity and competition; the disadvantages are laissez faire, hasty and loose [8].

Combined with the author's undergraduate teaching practice, this paper intends to carry out group teaching in the teaching of different courses such as basic discipline course "Botany", professional course " Animal and Plant Quarantine ", practical teaching "Botany Teaching Practice", summarize its experience, evaluate its effectiveness, reflect on its gains and losses, and hope to pass specific cases, Explore a set of scientific and effective teaching methods for undergraduate agriculture related education in Colleges and universities.

\section{Curriculum Design}

Undergraduate courses include professional compulsory courses and elective courses. The teaching objects of different courses have different understanding of the teaching content at the beginning of learning. Therefore, different from master's and doctoral students, it is necessary to arrange a certain number of teaching hours for undergraduates when designing the syllabus of a course, To introduce the key points of knowledge, overall framework and logical sequence of this course, including some basic concepts, professional theories, cutting-edge research and specific skills. The most important thing is that this step makes preliminary preparation for group teaching and makes necessary teaching demonstration for students.

For example, when teaching "Botany", teachers should reasonably arrange demonstration classes to explain the morphological characteristics and physiological functions of plant cells and tissues, the morphological structure and development of plant vegetative organs, roots, stems and leaves, and the basic theories and methods of plant classification; Similarly, the course of "Animal and Plant Quarantine" is taught to teach the basic knowledge of quarantine approval, entry-exit quarantine and quarantine treatment technology of China's inbound and outbound animals and plants and their products, as well as various quarantine infectious diseases and parasitic diseases of animals. Through teaching, students can understand these professional terms and concepts in advance and have a clear understanding of the teaching objectives of the course, so that they can have a basis and focus in the subsequent grouping, deeply understand and understand the project tasks, and make mistakes when completing the project, so as not to deviate from the topic.

Teachers teach basic concepts and theories first, and carry out certain preparation and demonstration work before group teaching, which should be reflected in teaching design and class arrangement. For the teaching of master's and doctoral students, the demonstration class hours of teachers shall be arranged for at least $2 \sim 4$ class hours; In contrast, in the face of undergraduate teaching, at the beginning of the semester, teachers' teaching demonstration generally needs to occupy about 10 class hours of a course. In addition to the teaching in the previous weeks, it is also necessary to carry out group teaching in the middle and later stages of the semester, and introduce the specific tasks in an overall, macro and background manner, so as to adjust the direction and focus of students' completing project tasks and correct their deviations. For example, in the teaching of "botany", teachers explain the basic theories and methods of plant classification in advance; In the later group teaching stage, explain the morphological characteristics and physiological functions of plant cells and tissues, and the morphological structure and development of plant vegetative organs, roots, stems and leaves. Teachers teach and students explain in groups in turn, which can not only guide and demonstrate operations, deepen and strengthen knowledge, but also change the rhythm of teaching and activate the atmosphere of the classroom, Avoid the monotony of a teaching stage.

\section{Scientific Grouping}

Different educational ideas have different methods for how to group. Talented educators advocate accelerated group teaching; Those with equal opportunities advocate the implementation of corrective group teaching; Those who teach students according to their aptitude emphasize further study - corrective is limited to grouping. Grouping can be divided into groups according to students' ability or level [9], or according to the cross combination of excellent, good, medium and poor grades [10]. The former can improve the teaching effect, while the latter can realize the homogenization between groups, so as to make synchronous progress and compare the teaching effect. There are three grouping methods: one is forced grouping by teachers; Second, students should make their own choices; The third is dynamic grouping. First, students can group freely, and then each student can choose again according to the learning situation of each group [11].

Voluntary grouping and cross grouping of special ability are suitable for school teaching. Different from the fixed class teaching in primary and secondary schools, head teachers and course teachers have a deep understanding of students' learning history, learning status and personality characteristics. In addition to administrative class teaching for a limited number and proportion of professional compulsory courses, most professional elective courses and public elective courses have students from different majors and grades, Even different colleges and universities, students' foundation, background and personality are different. In the face of this temporary collective, it is impossible to require any teacher to have an in-depth and continuous understanding of students. Therefore, teachers' intervention in compulsory grouping will bring many disadvantages. It is better to let them group freely and voluntarily in advance, form groups according to the specified number of groups, and make limited and appropriate 
fine-tuning in the subsequent teaching in combination with students' classroom performance and special practical ability. This spontaneous and voluntary group approach is not only in line with the characteristics of College Students' personality growth, but also conducive to the division of labor and cooperation of members in the group.

Of course, many college students use the same and fixed combination in different courses, mostly grouped according to intimate relationships such as dormitory members, classmates and majors, which hinders them from carrying out wider social communication, thus limiting their socialization process on campus. In view of this situation, teachers should encourage students to break this fence and suggest making new friends in learning; At the same time, it is required to consider gender composition when grouping, so as to facilitate gender balance, promote students to understand and understand the opposite sex in group learning, give full play to the characteristics and advantages of different genders, and develop heterosexual friends in common learning, so as to facilitate the physical and mental health and all-round development of college students.

When grouping, the teacher should introduce the requirements of the project tasks to the students in advance, so that the students can consider the skills and talents of the members in the group, and then they can do their best to learn from each other and complete the specified project tasks happily. For example, in the "botany teaching practice" and other practical courses involving the completion of specimen making projects, because the division of labor and cooperation of team members are required to complete the work of plant collection, specimen making, photography and so on, students with different specialties and skills can learn from each other, help each other and coordinate the division of labor, Finally, complete the teaching task with high quality. However, such grouping does not take the results of the previous final paper as the only standard to measure students' ability and level. Therefore, we should encourage everyone to participate in the activities with a responsible attitude and full passion, so as to form a homogeneous group with little difference between groups on the whole, which is conducive to intra group cooperation and inter group competition, and finally improve students' sense of responsibility and self-confidence.

It is better to implement the team leader responsibility system. The elected or rotating team leader is responsible for coordinating the division of labor and cooperation within the team, so as to strengthen the communication with the teachers. Only through the selection of group leaders rather than those designated by teachers can their command and coordination have a mass basis, so as to ensure the unity and concerted efforts of the students in the group to complete the task. If there are multiple project tasks in a semester, the rotation method can be considered to appropriately meet the individual's sense of honor, initiative and vanity, so as to cultivate more students' organizational ability, leadership ability, interpersonal communication ability and activity planning ability.

\section{Project Driven Group Teaching}

The purpose of group teaching is to change the traditional "full house" teaching method, turn the teacher leading type into the student leading type, stimulate the students' initiative and creativity by designing a number of appropriate and difficult project tasks, strengthen and deepen their understanding and mastery of a discipline's knowledge, theory and skills in the process of completing the project tasks, and finally be flexible Achieve the teaching objectives of this course vividly and efficiently [12].

Arrange clear group project tasks and set reasonable phased teaching objectives to adapt to the existing abilities and levels of most students [6]. In this way, we can not only avoid students from "not enough to eat". It can not stimulate their interests and challenges, but also avoid students from "unbearable", exceeding students' tolerance threshold, simply losing confidence and giving up trying.

Therefore, the set team project tasks include some basic tasks and some expansion tasks, which are driven and measured by flexible indicators. For example, in the teaching of the course "animal and plant quarantine", the basic theories and regulations of animal and plant quarantine need students to remember the relevant information, and the group is required to complete the flow chart and memory, which is the basic task; For various quarantine infectious diseases and parasitic diseases of each animal, the team is also required to write the summary of the causes of diseases and pests and preventive measures. This project task of combining objective and subjective topics gives students sufficient flexible space, so that they can combine point and area and strive for perfection. It not only examines the students' mastery of knowledge, but also trains the students' comprehensive ability of logical thinking and language expression.

Therefore, the assigned project tasks should not only achieve the teaching objectives of the course, but also conform to the students' training plan, but also conform to the macro positioning of the school. The "botany" and "animal and plant quarantine" courses taught by the author guide students to start from around, pay attention to special quarantine pests and weeds in Northwest Hebei, require students to make field samples of animal and plant materials, understand their growth characteristics, and finally make video product display. This process not only completes the teaching task of the course, integrates into the professional cultivation goal of college and department grass science, but also conforms to the positioning of the University's Applied University, so as to integrate theory with practice, deepen theoretical learning in practical operation, and cultivate special skilled talents to meet the needs of new agricultural science.

\section{Objective Evaluation to Ensure the Effect of Group Teaching}

In group teaching, after receiving the tasks, each group decomposes them within the group, divides work and cooperates to complete the specified projects, and finally 
submits the results presented by the teacher or class in the form of homework, special explanation, visual works, etc. Effective evaluation of their work attitude and achievement quality, determination of strict scoring mechanism and improvement of fair reward and punishment means can not only improve the teaching effect of follow-up classroom and effectively consolidate the achievements of group teaching, but also encourage students to actively invest in their future study and work with a good attitude [13, 14].

Evaluate the completion of group projects as the course achievements of groups and students. Generally speaking, students' self-evaluation, group mutual evaluation and teachers' comments can be adopted to promote the in-depth development of group teaching openly and fairly. In the specific operation, the evaluation methods adopted for courses of different nature and project tasks at different stages should be emphasized. For example, in the group teaching of "botany" and "animal and plant quarantine", in addition to encouraging mutual supervision among groups, teachers should make timely and pertinent comments according to the actual effect of task completion, so as to set an excellent example and guard against prevarication and perfunctory. For another example, at the end of the semester, when different groups submit animal and plant specimens and video works, all students can be arranged to watch them together, have a heated discussion on the advantages and disadvantages, and gradually form a relatively objective evaluation of each group's works in the mutual evaluation.

In undergraduate group teaching, the final task of evaluation project is to evaluate each group and its members. According to the completion of the learning task, give a comprehensive evaluation on the performance of each group in learning attitude, learning methods, learning ability, learning effect, etc., focusing on group evaluation. At the same time, combined with the division of labor, all members evaluate the performance of the group members, and the evaluation process runs through the whole process of completing the task [15]. In this process, class teachers need to figure out the psychology of students, pay attention to stimulating the awareness of competition and cooperation among groups, strive to eliminate the phenomenon of "free riding" in groups, and eliminate the possibility of "collusion and drainage" between groups. At the same time, they also need to pay attention to the unity, friendship and mutual assistance of classes on the premise of adhering to principles, so as to avoid malicious dismantling Deliberate sabotage and unfair competition.

The author once tried to carry out the memory evaluation of knowledge points among groups, but unfortunately found that outside the vision of teachers, groups did not really implement the evaluation tasks and gave each other high scores, which deviated from the original intention of group mutual evaluation. The division of tasks, such as in specimen making, will be ignored and go their own way. Therefore, the validity of inter group evaluation can be controlled to a certain extent by punishing the behavior of "releasing water" by means of random inspection by teachers; When completing the project tasks in stages, certain indicators are used to encourage and standardize the whole process participation of team members. For example, whether the team members are the team leader or not, each team member is required to complete the division of tasks on time. In this way, we can pool our wisdom and wisdom. Although the specific division of work performs its own duties, all team members are required to participate in the whole process, Contribute to the whole process of completing the project tasks, earnestly learn from the good in operation, and improve knowledge, vision and skills in mutual assistance.

Naturally, the overall evaluation of the group is taken as an important basis to determine the average score of the group. The scores of individuals in the group also depend on the contribution of the group, the completion of division of responsibilities, and the specific performance of special lectures. The scores of the group leader can be appropriately increased or decreased according to the quality of task completion, so as to reflect the level of management and organization. In short, the results of members in the group should be different, so as to eliminate the suspicion of "eating a big pot" and realize the performance distribution principle of distribution according to work and more contribution.

\section{Conclusion}

Whole process indoctrination teaching is the most popular and ineffective teaching method for college teachers today. As a result, even if the teacher is full of passion, the students may still be indifferent. Group teaching is to change the situation of "one speech hall" of teachers, mobilize students to actively participate, and change the traditional "preaching" of teachers into "understanding" of students in professional practice and independent thinking through division of work and cooperation within groups and competition and answer among groups, The traditional "cramming" teaching is changed into a combination of "heuristic", "discussion" and "comment" teaching, in order to promote the cognition, digestion, mastery and absorption of knowledge and skills.

Undoubtedly, the practical implementation of group teaching can combine teaching with fun, activate the classroom atmosphere, stimulate students' creativity and potential, change passive learning into active learning, and effectively improve the teaching quality and teaching effect. As long as we improve the mechanism, closely monitor and eliminate the disadvantages in the implementation process, group teaching can promote teamwork, promote the communication between teachers and students, and even improve the relationship between students; Cultivate the sense of competition, enhance the sense of belonging and honor, so as to form a cohesive force within the class. In addition, group teaching can also promote the application of learning, meet the realization of self-worth, and accumulate practical experience for future graduation design and future work, which is conducive to promoting the all-round development of students' comprehensive quality. 


\section{References}

[1] Shi Rui (2015). Research on the application of group teaching to research-based learning in College Classroom. Journal of Liaoning Educational Administration Institute, 5: 47-49.

[2] Yan Fang (2021). Strategy analysis of mathematics group teaching in primary school. Kaoshi Zhoukan, 14: 83-84.

[3] Sumitra Govindarajan, Sujatha Rajaragupathy, Kavitha Subramanian et al. (2021). Effectiveness of team teaching in biochemistry lectures for undergraduate students. Biochemistry and Molecular Biology Education, 49 (4): 583-587.

[4] Jing Chan (2009). On the function of group teaching in Colleges and Universities. Technology Information, 6: 132.

[5] Chen Dongyun (2005). Using group teaching to activate classroom atmosphere. Shanxi science and technology, 3: 78-79.

[6] Ge Jinwen (1994). Research on the characteristics, mode and operation technology of group teaching in class. Shanghai Education and scientific research, 1: 12-15.

[7] Sun Zufu (1992). Group teaching mode. Foreign educational materials, 1: 1-6.

[8] Ren Yanxing (2012). Reflection on the advantages and disadvantages of group teaching. Science and technology horizon, 26: 205, 353 .

[9] Ju Yufeng (2020). Thoughts on constructing junior middle school mathematics group teaching based on students' differences. Xin ke cheng, 41: 121.

[10] Fu Jiawei (2019). Application of homogeneous grouping in building learning community. OPEN CLASS Teachers'Version, 6: 160 .

[11] Zhong Yanfang (2020). Research on the application of dynamic group teaching in Chinese teaching in junior middle school. Scientific Consult, 17: 210.

[12] Liang Bin, Wang Jiaqin (2020). Application research and practice of task driven group teaching method in production practice teaching. China Educational Technology \& Equipment, 8: 129-131.

[13] Qi Xiehong (2013). Application of multiple evaluation in biology group experiment course in Senior High School. BIOLOGY TEACHING, 12: 14-15.

[14] Zheng Yuelong, Rao Li, Yan Qinghua et al. (2017). Research on multiple evaluation system of students' achievement in group teaching. Kaoshi Zhoukan, 47: 56.

[15] Wang Yuxiang, Quan Fujun, Wang Huanzhen (2011). Research and evaluation on group teaching of experimental courses of Social Work Specialty. CHSSCD Journal of Shandong Youth University of Political Science, 9: 138-142. 